Research paper

\title{
Improving quality and safety during intrahospital transport of critically ill patients: A critical incident study
}

\author{
Lina Bergman, RN, MSc ${ }^{\text {a, * }}$ \\ Monica Pettersson, RN, PhD ${ }^{\mathrm{a}, \mathrm{b}}$ \\ Wendy Chaboyer, RN, PhD ${ }^{\text {a, c }}$ \\ Eric Carlström, RN, PhD ${ }^{\text {a, d }}$ \\ Mona Ringdal, RN, PhD a, e \\ a Institute of Health and Care Sciences, Sahlgrenska Academy, University of Gothenburg, PO Box 457, SE-405 30, Gothenburg, Sweden \\ ${ }^{\mathrm{b}}$ Vascular Department, Sahlgrenska University Hospital, SE-413 45, Gothenburg, Sweden \\ c Menzies Health Institute Queensland, G40 Griffith Health Centre, Level 8.86, Gold Coast Campus, Griffith University, QLD 4222, Australia \\ d University of Southeast Norway, Vestfold, Postbox 235, 3603 Kongsberg, Norway \\ e Department of Anaesthesiology and Intensive Care, Kungälvs Hospital, SE-442 83, Kungälv, Sweden
}

\section{A R T I C L E I N F O R M A T I O N}

\section{Article history:}

Received 24 September 2018

Received in revised form

29 November 2018

Accepted 11 December 2018

\section{Keywords:}

Critical incident technique

Intensive care unit

Intrahospital transport

Nontechnical skills

Patient safety

Teamwork

\begin{abstract}
A B S T R A C T
Background: Intrahospital transport is a high-risk procedure for critically ill patients, yet there is little known about how the transport team manages critical incidents that occur.

Objectives: The aim of this study was to explore critical care nurses' and physicians' experiences and practices associated with critical incidents during the transfer process in critically ill patients.

Methods: As a part of an ethnographic study, semistructured interviews were performed using the critical incident technique. Data were collected in two intensive care units at one university hospital in a Swedish metropolitan city. Critical care nurses $(n=15)$ and physicians $(n=5)$ were interviewed, together describing a total of 46 critical incidents. Data were analysed using qualitative content and thematic analysis approaches.

Results: Content analysis of nurses' and physicians' practices resulted in a description of requirements for safe transports, including organisational prerequisites, professional skills and attributes, as well as actions and behaviours of safely performing transfers. Exploring the experiences of nurses and physicians in transporting critically ill patients yielded three main themes. The first theme, a hazardous process, revealed how caring for critically ill patients during intrahospital transfers was perceived as an unsafe, demanding task that presents several threats to the patient's safety. However, despite worries and concerns, participants trusted their own abilities to handle unexpected events, resulting in the second theme, performing when it matters. The third theme, towards safe practice, captured suggestions for improvement and attitudes towards existing safety hazards.

Conclusions: To prevent and manage critical incidents during intrahospital transport, findings of this study suggest that nontechnical skills such as situational awareness and teamwork are essential. In addition, the team must possess the requisite technical skills and knowledge to undertake transports. Finally, organisations are required to provide a supportive and sustainable transport environment that includes fewer transport-related hazards.
\end{abstract}

๑) 2018 Australian College of Critical Care Nurses Ltd. Published by Elsevier Ltd. All rights reserved.
Abbreviations: CCN, critical care nurse; IHT, intrahospital transport; ICU, intensive care unit.

* Corresponding author at: Institute of Health and Care Sciences, PO Box 457, SE405 30, Gothenburg, Sweden.

E-mail addresses: lina.bergman@gu.se (L. Bergman), monica.pettersson@gu.se (M. Pettersson),w.chaboyer@griffith.edu.au (W. Chaboyer), eric.carlstrom@gu.se (E. Carlström), mona.ringdal@fhs.gu.se (M. Ringdal).

\section{Introduction}

In recent years, patient safety has been recognised as a public health concern and a top priority in healthcare, ${ }^{1}$ including critical care. $^{2}$ The environment of the intensive care unit (ICU) is complex and fast paced, thereby presenting several patient safety 
challenges. Moreover, critically ill patients may be more vulnerable to iatrogenic injuries because of the severity and instability of their illness, as well as frequent need of medications and other interventions. ${ }^{3}$ Intrahospital transport (IHT), when patients are transferred from one setting to another within the same hospital to undergo diagnostic and therapeutic procedures, is a complex, highrisk procedure for critically ill patients. ${ }^{4}$ Complications, mishaps, and adverse events, defined as injuries caused by healthcare management rather than by the patient's underlying disease, ${ }^{5}$ have been estimated to occur in up to $80 \%$ of all IHTs. ${ }^{6,7}$ However, little is known about how critical care nurses (CCNs) and physicians in the ICU manage critical incidents that might occur during IHT. In this study, the focus was on practices to prevent and manage critical incidents during IHT.

Internationally, CCNs constitute the basis of the IHT transport team. ${ }^{8}$ Together with physicians and other healthcare staff, nurses strive to deliver the same standard of care, including monitoring and interventions, that is available in the ICU. ${ }^{9}$ The primary responsibility of CCNs during IHTs is to constantly monitor the patient and prompt interventions ${ }^{9}$; thus, they are ideally positioned to identify, prevent, and correct hazards before harm is caused to the patient. ${ }^{10}$ However, to improve safety, healthcare delivery systems need to be designed to support the performance of healthcare professionals. ${ }^{11}$ Hence, collecting information about the performances of those working at the sharp end (i.e., close to patient care) will provide opportunities to redesign systems and may be one way to facilitate improvements in the IHT process. The aim of this study was therefore to explore CCNs' and physicians' experiences and practices associated with critical incidents during the IHT process in critically ill patients.

\section{Methods}

\subsection{Study design and setting}

This research is based on a constructivist paradigm, acknowledging that knowledge is produced between individuals, and influenced by sociocultural contexts and structural conditions. ${ }^{12}$ As a part of a larger ethnographic study, in-depth qualitative interviews were conducted using the critical incident technique. ${ }^{13}$ The critical incident technique can be used to understand effective and ineffective performance, with the aim of providing solutions to practical problems. ${ }^{14}$ A critical incident is defined as a significant or important event where the person(s) involved can make a judgement about the positive or negative impact the incident has on the outcome of the situation. ${ }^{15}$ The present study was undertaken in two ICUs located at a university hospital in Sweden; one ICU specialised in trauma and general intensive care (18 beds), and the other ICU specialised in neurologic intensive care ( 8 beds). During 2016, the units performed a total of 1483 IHTs. ${ }^{16}$ In both ICUs, each CCN cared for two patients (nurse-to-patient ratio 1:2) with the help of one assistant nurse. The IHTs were mostly undertaken by CCNs and assistant nurses, and sometimes also by a physician. The ICUs had no specialised transport team. The Regional Ethical Review Board in Gothenburg approved the study (Dnr 103015).

\subsection{Participants}

The CCNs and physicians were recruited for face-to-face interviews by the first author (L.B.). Purposive sampling was used, ${ }^{17}$ aiming for maximum variation in age, sex, and extent of work experience among participants. Inclusion criteria were that the participant was either a CCN (i.e., a registered nurse with 1 year of additional education in critical care at university level) or a physician, either a specialist or resident in anaesthesia or acute care. Potential participants were given oral and written information about the study design and purpose, and they were invited to participate in the study. Written informed consent was collected before the interviews were conducted. A total of $23 \mathrm{CCNs}$ and physicians were invited to participate; of these, three declined. The most common reason for nonparticipation was lack of time.

\subsection{Data collection}

Data were collected between February and May 2016. Individual semistructured interviews, conducted by the first author (L.B.), were carried out in private at the hospital site. According to the critical incident technique, participants were asked to describe one or more critical incidents (i.e., significant or important events) that they had experienced during an IHT. Probing questions were asked to gain a complete understanding of the incident, how the persons involved acted, and the outcome of the incident. The interview guide was pilot tested and developed during the study period. The interviews lasted between 18 and $38 \mathrm{~min}$, and reflective notes were made after the interviews were completed. All interviews were audio taped and transcribed verbatim by the first author (L.B.). Data collection continued until data saturation was reached (i.e., no new information emerged).

\subsection{Data analysis}

Data were analysed using both content analysis ${ }^{18}$ and thematic analysis $^{19}$ approaches. The analysis was performed in three steps. First, the data were read and reread by the first, second, and last author (L.B., M.R., and M.P.) to become immersed in the data and obtain a sense of the whole. Critical incidents were identified and classified according to their apparent contributing factors. Second, inductive content analysis was used to analyse the practices related to critical incidents. Using open coding, text units were assigned a code whereby a few words indicated its basic contents. These codes were grouped, forming subcategories and then categories. Third, thematic analysis was used to analyse participants' experiences of the IHT process. In this analysis, data focusing on experiences (i.e., personal encounters, observations, and impressions) were extracted and coded. Codes were generated, compared, and combined to form subthemes and themes. These were then reviewed and refined, both in relation to each coded data extract and to the entire data set (i.e., all data used for the analysis). The analysis was primarily performed by the first author (L.B.), with the coauthors (M.P., W.C., E.C., and M.R.) contributing to refining the credibility ${ }^{20}$ of the categories, subthemes, and themes. NVivo (Version 11; QSR International Pty Ltd., Melbourne, Australia) software was used for data management.

\subsection{Rigour}

This study was reported adhering to the standards for reporting qualitative research guidelines. ${ }^{21}$ The first author (L.B.) was a CCN undertaking her doctorate studies. The coauthors (M.P., W.C., E.R., and M.R.) were experienced researchers with knowledge and training in the research methods used. The primary researcher (L.B.) and her interest were known to the participants; however, she had no prior relationship to participants or the study setting before data collection started. Trustworthiness of the findings was ensured by providing a clear description of the context, participant characteristics, and analysis process to enhance and facilitate transferability of the research findings and also by presenting a link between the data and results to demonstrate credibility and enhance transparency. A reflexive approach was applied 
throughout the research process, aiming to acknowledge and minimise subjective bias. ${ }^{20}$

\section{Results}

A total of 20 CCNs and physicians were interviewed (Table 1), who together described a total of 46 incidents. Each participant contributed between one and six critical incidents. Almost one in four of the critical incidents described was related to clinical deterioration of the transported patient (24\%), followed by critical incidents related to miscommunication and/or problems with cooperation (17\%), as well as smooth transport characterised by preparedness and good cooperation (17\%) (Table 2).

\subsection{Practices related to critical incidents}

Three categories, organisational prerequisites, professional skills and attributes, and behaviours and actions to perform transfers safely, supported by 12 subcategories, were generated from the content analysis of participants' practices related to critical incidents during IHT (Table 3). Analysis of the relationships among the emerging categories led to a preliminary model of requirements for safe IHT (Fig. 1). Organisational prerequisites influenced both professional skills and attributes as well as behaviours and actions to perform transfers safely. Furthermore, professional skills and attributes were affected by organisational prerequisites and influenced the behaviours and actions undertaken. Hence, behaviours and actions undertaken by the team and by individual team members were affected by both organisational prerequisites and professional skills and attributes.

\subsection{Experiences of the IHT process}

Three themes, a hazardous process, performing when it matters, and towards safe practice, and ten subthemes arose from the thematic analysis of participants' experiences of transporting critically ill patients within the hospital (Table 4). Themes and subthemes contributed to an overall understanding of an IHT as a hazardous process that presents several threats to the patient's safety. Therefore, healthcare professionals who perform IHTs felt the urge to protect the patient, which requires individual skills and responsibilities as well as a shared responsibility within the team. Despite the awareness that most IHTs were performed successfully without the occurrence of critical incidents, IHTs were described as demanding, unsafe tasks requiring time and resources. To feel safe when caring for patients in settings outside the ICU, specific requirements include the ability to trust in one's own competence, trust one's team, and trust in the systems involved to support the task. Themes and associated subthemes are presented in the next section.

Table 1

Characteristics of participants $(n=20)$.

\begin{tabular}{ll}
\hline Characteristic & Frequency (\%) \\
\hline Profession & $15(75)$ \\
Critical care nurse & $3(15)$ \\
Physician, specialist & $2(10)$ \\
Physician, resident & $15(75)$ \\
Sex, female & Median (range) \\
& $38.5(27.0-65.0)$ \\
Age (years) & $4.5(0.2-26.0)$ \\
Experience in ICU (years) &
\end{tabular}

\subsubsection{A hazardous process}

The first theme reveals how caring for critically ill patients during IHTs differs from caring for patients in the ICU setting. The familiar ICU environment, which includes having nearby support from colleagues when needed, provides security. Hence, being away from the ICU was associated with insecurity of staff. The three subthemes, outside the safe ICU setting, compromising patient safety, and a demanding task, describe different aspects of the theme that contribute to the overall understanding of an IHT as 'a hazardous process'.

In the first subtheme, outside the safe ICU setting, participants disclosed their worries and concerns about transfers. IHTs were often described, especially by CCNs, as 'one of the worst things we do'. Between the ICU and the destination site, participants felt vulnerable, exposed, and alone in hallways and elevators. They felt far away from other colleagues and resources (such as standard equipment) if an incident were to occur.

"If problems occur, you don't want to be standing in a hallway or in the elevator." (4)

Nonetheless, participants also perceived that most transports were performed successfully. Some participants therefore reflected on the validity of their worries and concerns related to the IHT process.

"Actually, considering the number of transports we perform, it is quite seldom that something occurs. We are experienced and we are quite good at [performing IHTs]. But, things can occur that you can't influence, and then it becomes more problematic." (8)

The second subtheme, compromising patient safety, showed that when problems occurred during IHTs (e.g., equipment failures), one of the consequences described was that the team had their focus drawn away from the patient to solve the problem. Once the problem was solved, the team members were often determined to continue the transport so that the planned examination or intervention could be performed. Afterwards, they sometimes reflected that it might have been better to abort the transport instead. Participants often expressed concerns about the patient's wellbeing and safety during an IHT. Some participants thought that patients most likely did not remember if a critical incident had occurred; thus, participants seldom described that they had informed the patient or relatives of the incident afterwards.

"Things happen quickly and when a problem was detected, it was also solved quickly; it took just a minute and then we were on our way again. But, you draw your attention away from the patient, and if something else were to occur, for example, if the patient's condition deteriorated... then your focus is somewhere else for a minute or a couple of minutes." (1)

The third subtheme, a demanding task, identified how IHTs affected participants' workload and working environment in the ICU. Participants described how they perceived an IHT as a physically demanding task that involves heavy lifting, unmanageable beds, and unsuitable working positions. The IHT also caused stress among participants, such as when incidents that they had not predicted occurred. In addition, participants were aware that there was a possibility that the transport itself would cause more harm to the patient than the possible benefits of the examination or procedure. Moreover, they recognised that being away from the ICU meant that the workload would increase for those colleagues left in the ICU and that the level of care for other patients might be affected. 
Table 2

Type of critical incident during intrahospital transport $(n=46)$.

\begin{tabular}{ll}
\hline Type of critical incident & Frequency (\%) \\
\hline Clinical deterioration of the transported patient & $11(24)$ \\
Miscommunication and/or cooperation problems & $8(17)$ \\
Smooth transport characterised by preparedness and good cooperation & $8(17)$ \\
Problems with medical treatment and/or drains and tubes & $5(11)$ \\
Nonfunctioning transport equipment & $4(9)$ \\
Nonfunctioning elevators & $4(9)$ \\
Misjudgement of competence needed & $3(6)$ \\
Hazards in the surrounding environment & $3(6)$ \\
\hline
\end{tabular}

Table 3

Categories and subcategories from content analysis.

\begin{tabular}{|c|c|c|}
\hline Categories & Subcategories & Verbatim quotes \\
\hline \multirow[t]{4}{*}{ Organisational prerequisites } & $\begin{array}{l}\text { Coordinate the } \\
\text { transport process }\end{array}$ & $\begin{array}{l}\text { "The transfer is the most vulnerable phase. Therefore, it's beneficial if we can spend as short a time as possible in } \\
\text { 'transit', i.e., perform as quick and smooth a transfer as possible. That means that the receiving unit needs to be } \\
\text { prepared and that both the receiving and departing units need to be synced. I believe that's a key to success and } \\
\text { something that hampers things when it goes badly." (19) }\end{array}$ \\
\hline & $\begin{array}{l}\text { Availability of } \\
\text { resources }\end{array}$ & $\begin{array}{l}\text { "You want to have someone with you that knows the routines, preferably three people. Then, if something were } \\
\text { to happen, one can always run for help and there would still be two people left with the patient." (14) }\end{array}$ \\
\hline & $\begin{array}{l}\text { Suitable transport } \\
\text { environment and } \\
\text { equipment }\end{array}$ & $\begin{array}{l}\text { "It would be beneficial to have the radiology department closer to the ICU, right next to it - to have as a short } \\
\text { distance as possible, and no elevators-as few elevators as possible and as close to help as possible, if something } \\
\text { were to happen." (15) }\end{array}$ \\
\hline & & $\begin{array}{l}\text { "It is a big advantage that we have the same surveillance monitor, the same ventilator, and the same infusion } \\
\text { pumps [as in the ICU]." (14) }\end{array}$ \\
\hline \multirow[t]{4}{*}{$\begin{array}{l}\text { Professional skills } \\
\text { and attributes }\end{array}$} & $\begin{array}{l}\text { Anticipate and } \\
\text { predict }\end{array}$ & $\begin{array}{l}\text { "Beforehand, go through everything that can go wrong so that you don't just send a patient out into the hallways } \\
\text { without thinking carefully: What might be a problem? What can happen between the ICU and receiving } \\
\text { department? [...]. All the time, I try to think proactively: What could happen during the next } 2 \text { min? Because } \\
\text { during exams you are not as close to the patient as in the ICU." (15) }\end{array}$ \\
\hline & $\begin{array}{l}\text { Maintaining } \\
\text { composure }\end{array}$ & $\begin{array}{l}\text { "When I started to work in the ICU, we always rushed during transport. I think this was because we did not like } \\
\text { to be away from the ICU with a critically ill patient. If something were to happen, you are quite alone. Then we } \\
\text { thought, the quicker we can complete the transport, the sooner we will be back at the ICU. But, it is not like that. } \\
\text { It is much better to take it slowly, step by step. That minimises the risk of unexpected events." (7) } \\
\text { "The stressful part is that I have to perform the transport quickly. I need to get down quickly and back quickly } \\
\text { because I have an additional patient. If I didn't have another patient, it would be different; but actually, I do have } \\
\text { another patient as well." (6) }\end{array}$ \\
\hline & $\begin{array}{l}\text { Knowledge and } \\
\text { experience }\end{array}$ & $\begin{array}{l}\text { "If the person attending doesn't have the knowledge required, they may not know our equipment so well and } \\
\text { they may not even have been in the radiology department. That means there are many new and unfamiliar tasks } \\
\text { for that person. Basically, knowledge is the key." (17) }\end{array}$ \\
\hline & $\begin{array}{l}\text { Transport team } \\
\text { competence }\end{array}$ & $\begin{array}{l}\text { "At that time, we were very lucky that there were two nurses attending the transport. At least I felt that. } \\
\text { Sometimes there is one nurse and two assistant nurses. Then you can get very lonely if you need help with } \\
\text { medication or something else." (16) }\end{array}$ \\
\hline \multirow[t]{7}{*}{$\begin{array}{l}\text { Behaviours and actions to } \\
\text { perform transfers safely }\end{array}$} & Plan and prepare & $\begin{array}{l}\text { "A successful transport... you should be well prepared beforehand and bring along all the things that you might } \\
\text { need. You should have people that you trust, and of course, have control over your patient. And you had to have } \\
\text { communicated with the receiving department 'At what time should we be there?' 'What should we do?' to } \\
\text { ensure that everybody knows what to do." (13) }\end{array}$ \\
\hline & $\begin{array}{l}\text { Cooperate and } \\
\text { communicate }\end{array}$ & $\begin{array}{l}\text { "I think we managed the incident well within the team. We followed the principles of ABCDE, protect the airway } \\
\text { first, and that's the most important! Then, we asked for help quickly." (2) }\end{array}$ \\
\hline & & $\begin{array}{l}\text { "You need to communicate: 'If you do that, I do this.' [... ] I believe that communication is the key, that everybody } \\
\text { knows what you are doing." (6) }\end{array}$ \\
\hline & Lead the team & $\begin{array}{l}\text { "The one responsible for the transport-there is always someone on the team that knows the patient, usually a } \\
\text { nurse, who also is responsible for the transport. That person has the overall responsibility for the patient's care, } \\
\text { no matter which situation might occur." (1) }\end{array}$ \\
\hline & $\begin{array}{l}\text { Adhere to assigned } \\
\text { team role }\end{array}$ & $\begin{array}{l}\text { "You need to communicate between the professions, to ensure that everybody knows their role, who is } \\
\text { responsible for what." (2) }\end{array}$ \\
\hline & & $\begin{array}{l}\text { "I think you need to work as a team. You should know beforehand who is responsible for what and how to } \\
\text { proceed." (6) }\end{array}$ \\
\hline & Follow routines & $\begin{array}{l}\text { "We know what to do; we have a well-prepared model to work accordingly, even [in the radiology department]. } \\
\text { Somehow, everybody knows all the steps. [...] I think it is because we have a routine, and we do it often." (14) }\end{array}$ \\
\hline
\end{tabular}

"I'm aware that during CT, the intracranial pressure might rise since the patient has to lie down, and I tolerate it. But still, it is quite stressful to see the [patient's] pressure rise high." (4)

Because IHT is a task requiring both human and nonhuman resources, performing transfers at night or on weekends was sometimes perceived as more stressful than performing IHTs in the daytime. Moreover, planned IHTs were avoided at night; therefore, when these did occur, the IHT tended to be urgent and the patient tended to be more unstable. However, the task itself was described as being similar to IHTs in the daytime.

\subsubsection{Performing when it matters}

Despite worries and concerns, participants felt confident that they could act effectively and in a timely manner when an incident occurred. Hence, participants trusted their own abilities to handle unexpected events (i.e., 'performing when it matters'). However, several requirements to feel confident and safe during IHTs were revealed. These are reflected in four subthemes. 


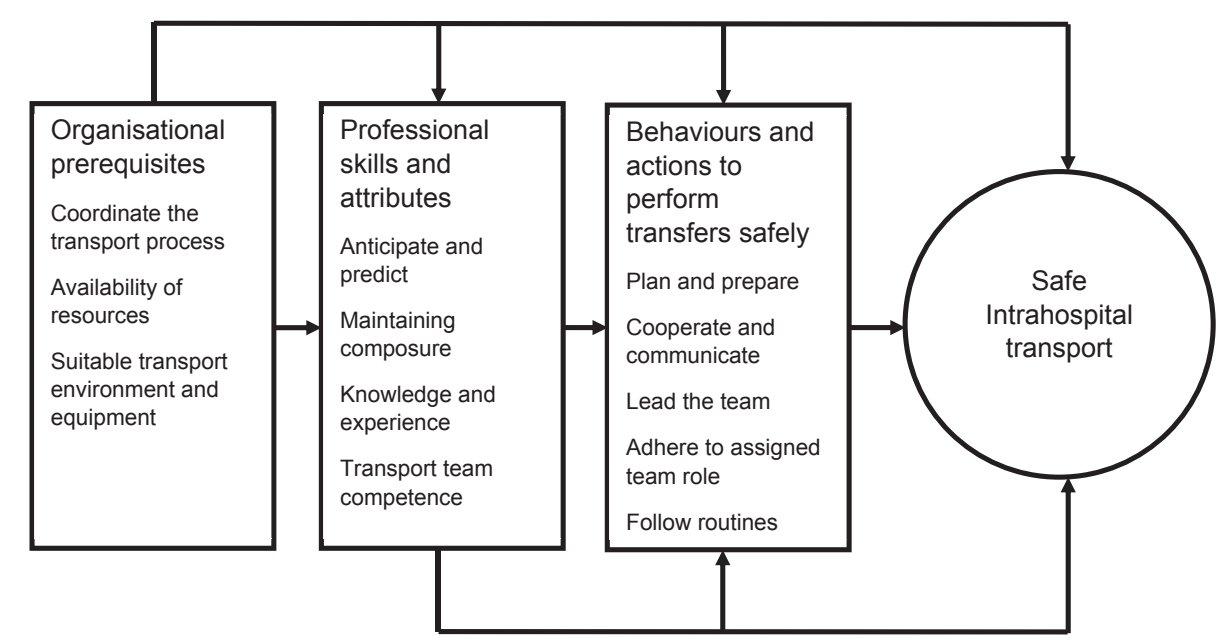

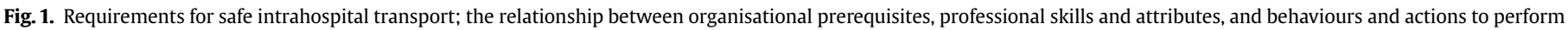
transfers safely.

The first subtheme, confidence in handling the unexpected, identified that participants trusted their own competence to act appropriately if an incident occurred. Notably, they often perceived that their actions had been adequate for the circumstances. When asked if they could have done something differently, participants often referred to actions or events that could have prevented the incident from happening. In addition, when they knew that they were able to handle unpredictable situations, participants felt more confident in performing IHTs.

"After 20 years, you have attended many, many transports. Therefore, you can predict a certain amount of things that might happen and you can prepare accordingly. Also, some things you know can't happen, which makes you feel more confident." (7)

After a critical incident, participants normally reflected on their actions. Sometimes they expressed feelings of frustration or regret for not being able to predict and prevent the incident from occurring.

"If something serious had happened to the patient, resulting in an actual adverse event, I would have taken it very personally because I was the one in charge, not just a team member." (2)

Furthermore, participants described that when a critical incident occurred, they acted according to their assigned team role, which was related to the subtheme trusting the team. Participants

Table 4

Themes and subthemes regarding healthcare professionals' experiences of transporting critically ill patients within the hospital.

\begin{tabular}{ll}
\hline Theme & Subtheme \\
\hline A hazardous process & $\begin{array}{l}\text { Outside the safe ICU setting } \\
\text { Compromising patient safety }\end{array}$ \\
& $\begin{array}{l}\text { A demanding task } \\
\text { Confidence in handling the unexpected } \\
\text { Performing when it matters }\end{array}$ \\
& Profting the team \\
& Safeguarding the patient \\
Towards safe practice & Overcoming hazards \\
& Interprofessional teamwork and \\
& collaboration across the hospital \\
& Intrahospital transport is not 'just routine' \\
\hline
\end{tabular}

ICU, intensive care unit. had to trust their fellow team members to have knowledge about their team role and responsibilities. However, teamwork was described as dynamic and subject to change, depending on the situation. For example, if the team leader was less experienced, other members of the team could support them in various ways. Hence, the value of being supported by other colleagues was often emphasised. The CCNs frequently expressed feeling supported when another CCN or a physician was also attending the transport. Novice CCNs felt supported when senior colleagues attended the transport.

"The feeling that you know each other and you know what to expect from each other, that everybody feels confident in his/her role and that we can trust each other if something were to happen [...]. This feeling of trust can be difficult to achieve when you are a new employee when you don't know your fellow colleagues well and they don't know you." (18)

The next subtheme, professional responsibilities, revealed how CCNs and physicians perceived their responsibilities differently. The CCNs described that they had overall responsibility for patient care during transports. This included being in charge of and coordinating the team's work. Physicians described their foremost responsibility as making a correct judgement regarding whether the patient should be transported or not. This included responsibility for colleagues as they did not want to expose the team to a hazardous situation. Physicians also described how their role on the team varied from being a team leader with full control over the team's work to being more of a consultant, attending for a special purpose, and helping when needed.

"As a physician, you might not give 100 percent attention during transports, even during those transports when you are present. During most transports, we don't attend at all. Then there is a sliding scale of when you attend and give your full attention." (9)

In the final subtheme, safeguarding the patient, participants described how the IHT process requires involvement from several different care providers within the hospital, such as staff from the radiology department or the operating theatre. However, CCNs and physicians from the ICU felt an overall responsibility for the patient's care. Moreover, they considered themselves to have the best knowledge regarding the patient's interests and specific needs. When conflicting interests occurred, they sometimes felt that they had to protect the patient, especially during examinations. 
"If the staff of the radiology department are experienced and used to handling our patients, there are seldom any problems. But sometimes, for example during on-call time [evening, nights, and weekends], they are less experienced. They might feel insecure about how to treat our patients. [...] Then you have to tell them." (6)

To protect the patient's best interests, CCNs sometimes had to get assistance from a physician. This was also described by physicians, who sometimes had to attend the transport for the purpose of making decisions and communicating its success to colleagues in other departments.

"Sometimes my role [as a physician] during transport is not to treat the patient but to be present to control the examination and see the Results straight away. Also, I might have to discuss the examination with the physician in the radiology department. There might be a need to call other specialists such as a neurologist or a surgeon straight away. Sometimes, I need to be there to make decisions that might be difficult for the nurse to make." (19)

\subsubsection{Towards safe practice}

The third theme describes important actions to progress 'towards safe practice' (i.e., to improve IHT safety). The three subthemes, overcoming hazards, interprofessional teamwork and collaboration across the hospital, and IHT is not 'just routine', capture suggestions for improvement and attitudes towards existing risks and hazards. Overall, the theme reveals the importance of correcting existing hazards before they cause patient harm. This requires actions by the individuals performing IHTs (such as enhanced collaboration) as well as organisational improvements, including improvement of attitudes towards IHT safety.

In relation to the first subtheme, overcoming hazards, participants emphasised the importance of learning from critical incidents to further improve the IHT process. Notably, some participants expressed feelings of frustration that incidents actually had to occur before the local management acted, even if an incident was caused by a well-known safety hazard. Others expressed that they were satisfied with how the local management handled their safety concerns. However, when experiencing a critical incident, participants were more likely to double-check the specific hazard involved in the next IHT, even if they knew that checking it might not be effective. Therefore, they had to trust that the systems involved, such as the elevators and other supportive resources, would work.

"Thus, you have to believe that the elevators will work. I'm quite cautious to check before departure that I bring, for example, the acute care bag and a telephone. But in this situation, could we have acted differently? I mean, we used the elevators one or two hours before [...]. So, I don't know... for sure we could have done something differently. Actually, no; I don't think so, not regarding the elevators." (10)

The second subtheme, interprofessional teamwork and collaboration across the hospital, shows the importance of teamwork and collaboration during IHTs. The CCNs often described that they wanted more interprofessional teamwork. This did not necessarily include having a physician present during every transport. Rather, they desired more engagement, such as physicians being available by phone or making a plan together on how to act if something happened. Physicians considered the CCNs qualified and competent to perform transports in most cases, without their assistance.

"In general, I appreciate when physicians are engaged before a transport, that they are present in the room and ask: 'Does everything feel okay? Do you have any questions?' Also, that he or she gives clear directives, so that I know what to do if something happens. Furthermore, I appreciate when physicians make themselves available, for example stating: 'Just call me if anything happens and I will be there straight away'." (2)

Moreover, participants described needing to trust in the expertise of others involved in the patient's care during IHT, for example, regarding a specific examination or intervention. Therefore, mutual respect towards the responsibilities across the hospital was highlighted as important to improvement.

Finally, participants described how performing IHTs was an integral part of participants' regular work in the ICU, reflecting the subtheme "intrahospital transport is not 'just routine'." The CCNs described that they became accustomed to being independently responsible for critically ill patients during transports. However, they also highlighted the need to consider transport a high-risk process.

"Actually, it is quite a big thing, but sometimes we don't think about it because we perform so many transports. But we leave the ICU with very sick patients out in the hallway and if something happens you are very vulnerable. Sometimes, we might not see it as risky as it is; we just go. But we should have more respect towards what we do. Actually, we walk away with a patient who is receiving a high dose of vasopressors and $80 \%$ percent oxygen on the ventilator, carrying only a small ventilator bag and a phone to call the doctor if needed." (13)

\section{Discussion}

This study explored nurses' and physicians' experiences and practices associated with critical incidents that occur during the transport of critically ill patients within the hospital. Requirements for safe IHT were identified, including skills and actions important to the prevention and management of critical incidents. To the author's knowledge, the strategies used by nurses and physicians to maintain safety during IHTs have not been identified and described previously. However, complementary to technical skills, nontechnical skills such as teamwork, situational awareness, and leadership, have been increasingly recognised as important for delivering safe and high-quality care, ${ }^{22-24}$ including in the critical care environment. ${ }^{25,26}$

In this present study, participants felt confident that they would act effectively and in a timely manner if and when an incident occurred. Notably, it became evident that situation awareness (described in this study as anticipating, predicting, and preparing accordingly) was perceived as an important practice for conducting safe IHTs. Situation awareness has been defined as the understanding of a situation and its possible outcomes. ${ }^{27}$ The concept involves gathering of information, interpretation and understanding of data, and predicting what can happen in the future. ${ }^{27}$ Situation awareness influences the decision-making process of how to respond to a situation and can be affected by factors such as experience of the task provider, task workload, and distractions or interruptions. ${ }^{24}$ Findings of this study concur with those of Fanara et al. ${ }^{28}$ who emphasised that anticipation, both regarding deterioration of the patient's condition and possible equipment and organisational complications, plays a key role in planning IHTs. Furthermore, present results implied that situational awareness is crucial to maintaining safety during the whole IHT process. Therefore, it is suggested that task workload, distractions, and interruptions should be minimised before and during IHTs. Also, attention should be paid to support healthcare professionals' 
abilities in anticipating, predicting, and preparing accordingly to different scenarios that might occur during IHTs.

In this present study, the importance of effective and wellfunctioning transport teams became evident. Both individual and collective nontechnical skills such as communication, team coordination, and team leadership were perceived as essential to performing safe IHTs. Apart from one recently published study by Latzke et al. ${ }^{29}$ indicating that good teamwork and a climate of safety reduce adverse events during IHTs, there are few studies investigating the effect of team performance on safety during IHTs. However, findings of this study are consistent with evidence demonstrating an association between high-quality teamwork and improved patient safety in critical care settings. ${ }^{26,30}$ Importantly, current findings imply that collaboration within the team, as well as improved interprofessional collaboration, might enhance IHT safety. Both improved nurse-to-nurse and nurse-to-physician collaboration have been significantly associated with better patient safety outcomes in acute care hospital settings. ${ }^{31}$ Hence, the effects of teamwork and collaboration on patient safety outcomes during IHTs need to be further investigated.

Required teamwork skills might differ according to the specific characteristics and type of team. ${ }^{32}$ Importantly, in addition to frequently facing various procedural and environmental safety hazards, ${ }^{33}$ IHT teams are composed of members that are constantly changing. ${ }^{29}$ A recent review by Ervin et al. ${ }^{34}$ on teamwork in the ICU points out that low temporal stability within teams can impede team dynamics. Furthermore, ICU teams often have to work in a physically and emotionally challenging environment; therefore, effort is needed to develop actionable interventions aiming to improve advanced team-based care in the ICU. ${ }^{34}$ This is in line with results of this study, implying that improving team performance could be one way to reduce transport-related incidents. Therefore, it is suggested that findings from the present study could inform future interventions aiming to improve teamwork during IHTs in critically ill patients.

In this present study, an IHT was described as a demanding, unsafe task requiring time and resources. These results are consistent with those of other studies concluding that IHTs influence the work environment of healthcare providers in the ICU. ${ }^{35,36}$ These findings are important because stress, fatigue, and high-level work demands are known to increase adverse patient outcomes $^{37,38}$ and might affect both teamwork and patient safety. ${ }^{39}$ In this present study, most critical incidents were perceived as being related to clinical deterioration of the transported patient (24\%), which may or may not be avoided. Safety concerns by healthcare professionals during IHTs must be recognised as they could potentially lead to errors. Moreover, applying a human factor approach, patient safety activities should not only mitigate hazards but also improve and support human performance. ${ }^{40}$ Hence, future interventions should include supportive actions for healthcare professionals alongside reductions in IHT-related safety hazards.

In addition to practices that are important for safe IHTs, organisational prerequisites such as suitable equipment and environments were identified which are critical for IHT safety and are amenable to improvement. Current findings confirm previously published findings regarding IHT safety. ${ }^{9,28}$ The use of different strategies, such as checklists, ${ }^{41,42}$ training interventions, ${ }^{43}$ and technical solutions, ${ }^{44}$ has been suggested to improve safety during IHTs. Therefore, it is suggested that future solutions for safe IHTs should include improving environmental and technical requirements alongside support of technical and nontechnical skills among members of the transport team. Furthermore, it was noted that patients were seldom informed when incidents occurred. Research has suggested that patient engagement in the ICU could contribute to safer care. ${ }^{45,46}$ For example, Dykes et al. ${ }^{46}$ found that implementation of a patient engagement program together with structured team communication in the ICU was associated with a reduction in adverse events and improved patient satisfaction. Consequently, patients' perceptions of and participation in the IHT process need to be further investigated.

The following limitations of this research must be acknowledged. First, the data collected were retrospective in nature and relied on participants' recollection of critical incidents. The ability to recall events differs among individuals and may become distorted over time. However, critical incidents were easily recalled for the most part, and detailed descriptions of the incidents were provided by participants. When complete details are given, it can be assumed that the information is accurate. ${ }^{47}$ Second, this study investigated how nurses and physicians perceived their actions related to critical incidents; no data were collected on whether these perceptions were consistent with their behaviours. Third, the number of critical incidents included in this study might be considered too small a sample to provide an accurate description of participants' behaviours and actions; ${ }^{13}$ however, more recent methodological studies have suggested that fewer events can provide sufficient information to be able to perform an adequate analysis. ${ }^{48}$ In the present study, data were collected until no new information was obtained and redundancy was achieved (i.e., data saturation was reached). Moreover, the scope of the study was well defined, and the topic being studied was obvious and clear to participants. ${ }^{49}$ This resulted in that critical incidents were richly described in a detailed manner, often containing numerous behaviours and actions related to the IHT process. Hence, the sample size and number of incidents included in the study appeared adequate for analysis.

\section{Conclusions}

The findings of the present study showed that a multifaceted approach is needed to perform IHTs safely. First, organisations need to provide a supportive and sustainable IHT environment, including adapted technology and equipment. Second, the transport team must possess the required technical skills and knowledge. Third, individual and collective nontechnical skills such as situational awareness and teamwork are essential to ensure that IHT safety hazards are anticipated and corrected before causing patient harm. These findings are important in that they highlight specific opportunities to support and improve performance among healthcare professionals, as well as the quality and safety of critically ill patients during IHT.

\section{Authors' contributions}

L.B. collected all data, analysed and interpreted the data, and drafted the manuscript. M.P., W.C., and M.R. contributed to conception and design of the study, data analysis and interpretation of results, and revision of the manuscript. E.C. contributed to conception and design of the study and revision of the manuscript. All authors read and approved the final manuscript.

\section{Funding}

L.B. received a PhD fellowship granted by the Institute of Health and Care Sciences, University of Gothenburg.

\section{Acknowledgements}

The authors would like to thank all healthcare professionals at the included ICUs for their participation, time, and support in this 
research. The authors also thank Edanz Group for editing a draft of this manuscript.

\section{References}

[1] Institute of Medicine. Crossing the quality chasm: a new health system for the 21st century. Washington, D.C.: National Academy Press; 2001.

[2] Garrouste-Orgeas M, Flaatten H, Moreno R. Understanding medical errors and adverse events in ICU patients. Intensive Care Med 2016;42(1):107-9.

[3] Rothschild JM, Landrigan CP, Cronin JW, Kaushal R, Lockley SW, Burdick E, et al. The critical care safety study: the incidence and nature of adverse events and serious medical errors in intensive care. Crit Care Med 2005;33(8): 1694-700.

[4] Beckmann U, Gillies DM, Berenholtz SM, Wu AW, Pronovost P. Incidents relating to the intra-hospital transfer of critically ill patients: an analysis of the reports submitted to the Australian Incident Monitoring Study in Intensive Care. Intensive Care Med 2004;30(8):1579-85.

[5] Kohn LT, Corrigan JM, Donaldson MS. To err is human: building a safer health system. Washington, D.C.: National Academies Press; 2000.

[6] Jia L, Wang H, Gao Y, Liu H, Yu K. High incidence of adverse events during intra-hospital transport of critically ill patients and new related risk factors: a prospective, multicenter study in China. Crit Care 2016;20:12. https://doi.org/ 10.1186/s13054-016-1183-y.

[7] Parmentier-Decrucq E, Poissy J, Favory R, Nseir S, Onimus T, Guerry MJ, et al. Adverse events during intrahospital transport of critically ill patients: incidence and risk factors. Ann Intensive Care 2013;3(1):1-10.

[8] Warren J, Fromm Jr RE, Orr RA, Rotello LC, Mathilda Horst H. Guidelines for the inter- and intrahospital transport of critically ill patients. Crit Care Med 2004;32(1):256-62.

[9] Day D. Keeping patients safe during intrahospital transport. Crit Care Nurse 2010;30(4):18-32.

[10] Henneman EA, Gawlinski A, Giuliano KK. Surveillance: a strategy for improving patient safety in acute and critical care units. Crit Care Nurse 2012;32(2):e9-18.

[11] Karsh BT, Holden RJ, Alper SJ, Or CKL. A human factors engineering paradigm for patient safety: designing to support the performance of the healthcare professional. Qual Saf Health Care 2006;15(Suppl 1):i59-65.

[12] Lincoln YS, Lynham SA, Guba EG. Paradigmatic controversies, contradictions, and emerging confluences, revisited. In: Denzin NK, Lincoln YS, editors. The SAGE handbook of qualitative research. 4th ed. Thousand Oaks: SAGE Publication Ltd; 2011. p. 97-128.

[13] Flanagan JC. The critical incident technique. Psychol Bull 1954;51(4):327-58.

[14] Schluter J, Seaton P, Chaboyer W. Critical incident technique: a user's guide for nurse researchers. J Adv Nurs 2007;61(1):107-14.

[15] Norman IJ, Redfern SJ, Tomalin DA, Oliver S. Developing Flanagan's critical incident technique to elicit indicators of high and low quality nursing care from patients and their nurses. J Adv Nurs 1992;17(5):590-600.

[16] Swedish intensive care registry. Intensivvårdsregistrets utdataportal [Internet]. 2017 [cited 2017 June 20] Available from: http://portal.icuregswe. org/utdata/.

[17] Teddlie C, Tashakkori A. Foundations of mixed methods research: integrating quantitative and qualitative approaches in the social and behavioral sciences. Los Angeles: SAGE Publications Ltd; 2009.

[18] Elo S, Kyngäs $H$. The qualitative content analysis process. J Adv Nurs 2008;62(1):107-15.

[19] Braun V, Clarke V. Using thematic analysis in psychology. Qual Res Psychol 2006;3(2):77-101.

[20] Krefting L. Rigor in qualitative research: the assessment of trustworthiness Am J Occup Ther 1991;45(3):214-22.

[21] O'Brien BC, Harris IB, Beckman TJ, Reed DA, Cook DA. Standards for reporting qualitative research: a synthesis of recommendations. Acad Med 2014;89(9): $1245-51$.

[22] Flin R, Maran N. Identifying and training non-technical skills for teams in acute medicine. Qual Saf Health Care 2004;13(Suppl 1):i80-4.

[23] Flin R, Patey R, Glavin R, Maran N. Anaesthetists' non-technical skills. Br J Anaesth 2010;105(1):38-44.

[24] Flin RH, O'Connor P, Crichton M. Safety at the sharp end: a guide to nontechnical skills. Aldershot: Ashgate; 2008.
[25] Reader T, Flin R, Lauche K, Cuthbertson BH. Non-technical skills in the intensive care unit. Br J Anaesth 2006;96(5):551-9.

[26] Dietz AS, Pronovost PJ, Mendez-Tellez PA, Wyskiel R, Marsteller JA, Thompson DA, et al. A systematic review of teamwork in the intensive care unit: what do we know about teamwork, team tasks, and improvement strategies? J Crit Care 2014;29(6):908-14.

[27] Mica RE. Toward a theory of situation awareness in dynamic systems. Hum Factors 1995;37(1):32-64.

[28] Fanara B, Manzon C, Barbot O, Desmettre T, Capellier G. Recommendations for the intra-hospital transport of critically ill patients. Crit Care 2010;14(3):R87. https://doi.org/10.1186/cc9018.

[29] Latzke M, Schiffinger M, Zellhofer D, Steyrer J. Soft Factors, Smooth Transport? The role of safety climate and team processes in reducing adverse events during intrahospital transport in intensive care. Health Care Manag Rev 2017. https://doi.org/10.1097/HMR.0000000000000188.

[30] Reader TW, Flin R, Mearns K, Cuthbertson BH. Developing a team performance framework for the intensive care unit. Crit Care Med 2009;37(5):1787-93.

[31] Ma C, Park SH, Shang J. Inter-and intra-disciplinary collaboration and patient safety outcomes in US acute care hospital units: a cross-sectional study. Int Nurs Stud 2018;85:1-6.

[32] Salas E, Burke CS, Cannon-Bowers JA. Teamwork: emerging principles. Int J Manag Rev 2000;2(4):339-56.

[33] Bergman LM, Pettersson ME, Chaboyer WP, Carlstrom ED, Ringdal ML. Safety hazards during intrahospital transport: a prospective observational study. Crit Care Med 2017;45(10):e1043-9.

[34] Ervin JN, Kahn JM, Cohen TR, Weingart LR. Teamwork in the intensive care unit. Am Psychol 2018;73(4):468-77.

35] Pope BB. Provide safe passage for patients. Nurs Manag 2003;34(9):41-6.

[36] Ringdal M, Chaboyer W, Warren Stomberg M. Intrahospital transports of critically ill patients: critical care nurses' perceptions. Nurs Crit Care 2015;21(3):178-84

[37] de Oliveira AC, Garcia PC, Nogueira LS. Nursing workload and occurrence of adverse events in intensive care: a systematic review. Rev Esc Enferm 2016;50(4):679-89.

[38] Hall LH, Johnson J, Watt I, Tsipa A, O'Connor DB. Healthcare staff wellbeing, burnout, and patient safety: a systematic review. PLoS One 2016;11(7): e0159015. https://doi.org/10.1371/journal.pone.0159015.

[39] Welp A, Meier LL, Manser T. The interplay between teamwork, clinicians emotional exhaustion, and clinician-rated patient safety: a longitudinal study. Crit Care 2016;20(1):110. https://doi.org/10.1186/s13054-016-1282-9.

[40] Carayon P, Xie A, Kianfar S. Human factors and ergonomics as a patient safety practice. BMJ Qual Saf 2014;23(3):196-205.

[41] Brunsveld-Reinders AH, Arbous MS, Kuiper SG, de Jonge E. A comprehensive method to develop a checklist to increase safety of intra-hospital transport of critically ill patients. Crit Care 2015;19:214. https://doi.org/10.1186/s13054015-0938-1.

[42] Jarden RJ, Quirke S. Improving safety and documentation in intrahospital transport: development of an intrahospital transport tool for critically ill patients. Intensive Crit Care Nurs 2010;26(2):101-7.

[43] Beigmohammadi MT, Rahimi M, Nabavian O, Davarani SH, Karvandian K, Kamalitabar F. Clinical course teaching in transport of critically Ill patients: small group methods. Acta Med Iran 2016:54(9):590-4.

[44] Joo KH, Yoo IS, Lee J, Kim SW, Ryu S, You YH, et al. Reduction of intra-hospita transport time using the easy tube arrange device. Clin Exp Emerg Med 2016;3(2):81-7.

[45] Davidson JE, Powers K, Hedayat KM, Tieszen M, Kon AA, Shepard E, et al. Clinical practice guidelines for support of the family in the patient-centered intensive care unit: American College of Critical Care Medicine Task Force 2004-2005. Crit Care Med 2007:35(2):605-22.

[46] Dykes PC, Rozenblum R, Dalal A, Massaro A, Chang F, Clements M, et al Prospective evaluation of a multifaceted intervention to improve outcomes in intensive care: the promoting respect and ongoing safety through patient engagement communication and technology study. Crit Care Med 2017;45(8): e806-13.

[47] Kemppainen JK. The critical incident technique and nursing care quality research. J Adv Nurs 2000;32(5):1264-71.

[48] Butterfield LD, Borgen WA, Amundson NE, Maglio AST. Fifty years of the critical incident technique: 1954-2004 and beyond. Qual Res 2005;5(4): 475-97.

[49] Morse JM. Determining sample size. Qual Health Res 2000;10(1):3-5. 